\title{
Diagnóstico ambiental e análise temporal do Córrego Bananal, município Gurupi, Tocantins.
}

\author{
Environmental diagnosis and thunderstorm Bananal stream analysis, municipality \\ Gurupi, Tocantins.
}

\author{
Bárbara Suelma Souza Costa' \\ Patrícia Aparecida de Souza²(*) \\ Rubens Ribeiro da Silva ${ }^{3}$
}

\section{Resumo}

As Áreas de Preservação Permanente (APP's), apesar de apresentarem inúmeros benefícios ao ecossistema, vêm sofrendo intensas degradações, sendo necessário conhecer e quantificar os impactos presentes nestas áreas, para se propor medidas mitigadoras destes impactos. O presente trabalho objetivou a realização de um diagnóstico ambiental as margens do Córrego Bananal, localizada na Fazenda Carolina 1 e 2, no município de Gurupi, TO. Os impactos presentes na área foram listados, utilizando o método "Check list” e classificados, utilizando a rede de interação e matriz de interação de Leoplod, posteriormente foi proposto medidas mitigadoras para recuperação dessas áreas. Para analisar a evolução da degradação às margens do córrego, realizou-se análise temporal nos anos de 1996, 2006 e 2016 utilizando o Sistema de Informações Geográficas (SIG). Os resultados obtidos mostraram que os principais impactos verificados foram: a supressão da mata ciliar, a invasão de espécies ruderais e exóticas, o assoreamento e a deposição inadequada de resíduos sólidos; a análise temporal demonstrou que o ano de 2006 apresentou maior degradação, quando comparada ao ano de 1996, ocasionada por uma intensa queimada. E que, no ano de 2016, parte da área já se encontrava em processo de regeneração cujas medidas mitigadoras proposta foram: a elaboração de um Plano de Recuperação de Áreas Degradadas (PRAD), a retirada da vegetação exótica, o isolamento de toda área ao redor da represa e o plantio de espécies nativas.

Palavras-chaves: áreas de preservação permanente; impacto ambiental; recuperação.

$1 \quad$ Mes.; Ciências Florestais e Ambientais; Universidade Federal do Tocantins, UFT, Brasil; E-mail: barbarasuelmacx@ hotmail.com

2 Dra.; Ciência Florestal; Universidade Federal de Viçosa, UFV, Brasil; Professora Assistente da Universidade Federal de São João Del Rei, do Departamento de Engenharia Florestal no Curso de Engenharia Florestal; Endereço: Universidade Federal de São João Del-Rei. Rua Sétimo Moreira Martins, 188. Bairro Itapuã, CEP: 77402970 - Sete Lagoas, MG Brasil; E-mail: patyapsouza30@gmail.com (*) Autor para correspodências

3 Dr.; Agronomia (Solos e Nutrição de Plantas); Universidade Federal de Viçosa, UFV, Brasil; professor pesquisador da Universidade Federal do Tocantins nos cursos de Agronomia e Mestrado em Produção Vegetal em Engenharia Florestal e Doutorado em Produção Vegetal; Endereço: Fundação Universidade Federal do Tocantins, Campus Universitário de Gurupi. Rua Badejos Lt. 07 Ch. 69/72 Zona rural. Zona Rural, CEP: 77402970 - Gurupi,TO - Brasil; E-mail: rrs2002@ uft.edu.br

\begin{tabular}{llllll}
\hline Ambiência & Guarapuava (PR) & v.I5 n.I & p. $173-193$ & Jan/Abr 20I9 & ISSN I808 - 025I
\end{tabular}




\section{Abstract}

The Permanent Preservation Areas (APP's) despite presenting numerous benefits to the ecosystem has been suffering from intense degradations. It is necessary to know and quantify the impacts present in these areas, to propose mitigating measures for these impacts. The present study aimed at conducting an environmental diagnosis the margins of the Bananal Stream, located at Fazenda Carolina 1 and 2, in the municipality of Gurupi, TO. The impacts present in the area were listed using the "Check list" method and classified using the interaction network and interaction matrices of Leopold, subsequently mitigating measures were proposed to recover these areas. To Analyze the evolution of the degradation, the margins of the stream were performed in the years 1996, 2006 and 2016 using the Geographic Information System (GIS). The results obtained showed that: the main impacts verified were, the suppression of the ciliary forest, the invasion of ruderal and exotic species, the siltation and inadequate deposition of solid residues, the temporal analysis demonstrated that the year 2006 showed higher degradation when compared to the year 1996, occasioned by an intense burnt. And that in the year 2016 part of the area was already in the process of regeneration and the mitigation measures proposed were: the elaboration of a Degraded Areas Recovery Plan (PRAD), the removal of exotic vegetation, the isolation of the entire area around the dam and the planting of native species.

Key words: Environmental Diagnosis, "Check list”, Interaction Network, Matrices of Leopold, Temporal analysis.

\section{Introdução}

O município de Gurupi, localizado no Estado do Tocantins, apresenta uma população estimada, em 2018, de 85.737 pessoas (IBGE, 2017) e encontra-se inserida dentro da área de duas bacias hidrográficas, do rio Formoso do Araguaia e do rio Santo Antônio. O córrego Bananal é um dos mananciais que o município possui, com uma represa utilizada de reservatório para abastecer a cidade. O lago é formado pelo represamento do córrego Bananal e possui cerca de 200 hectares, formando uma bela paisagem, distante cerca de 10 quilômetros de Gurupi (SALERA JÚNIOR, 2011).

Os Mananciais de água de Gurupi são as fontes superficiais ou subterrâneas, usadas para abastecimento humano e manutenção de diversas atividades econômicas (irrigação, processos industriais, etc.). Estes vêm sofrendo com o descaso e degradação desde os primórdios de sua ocupação da cidade, quando pequenos grupos familiares se instalaram próximo aos mananciais (SALERA JÚNIOR, 2011).

Proteger os recursos hídricos é dever e obrigação da comunidade como um todo e, ao mesmo tempo, deve ser visto como uma obrigação individual, de cada um, pois todos têm o direito de viver em um ambiente ecologicamente equilibrado e sustentável a longo prazo, incluindo a conservação e preservação da água (SALERA JÚNIOR, 2011).

Tem sido notável a crescente preocupação social no que diz respeito à utilização dos recursos naturais. E isso tem grande contribuição para o desenvolvimento de estudos que cooperem para criação de um pensamento moderno, que tenham como principal objeto de reflexão, o ambiente. 
Entre essas preocupações, encontram se as APP’S (Áreas de Preservação Permanente), os quais, de acordo com o artigo "3ํ do Código Florestal Federal (Lei n ${ }^{\circ}$ 12.651/2012), são definidas como áreas protegidas, cobertas ou não por vegetação nativa, com a finalidade de preservar os recursos hídricos, a paisagem, a estabilidade geológica e a biodiversidade, facilitar o fluxo gênico de fauna e flora, proteger o solo, e assegurar o bem-estar das populações humanas"(BRASIL, 2012).

Inseridas no contexto de APP estão às matas ciliares, que são vegetações que se encontram às margens de corpos d'água, como riachos, rios, lagoas, lagos, represas e nascentes, exibindo, habitualmente, porte arbóreo ou arbustivo em ambientes não perturbados (Jacomassa, 2010). Castro et al.,(2013) relatam que as vegetações ciliares compõem um grande suporte de segurança que auxilia no equilíbrio do ecossistema e suas relações intrínsecas, estão ligadas ao manejo e conservação dos recursos naturais.

Resumidamente, a importância da existência de florestas ciliares ao longo dos rios, ao redor de lagos e reservatórios, baseiam-se nos inúmeros benefícios que estas trazem ao ecossistema, desempenhando função de proteção sobre os recursos naturais bióticos e/ou abióticos.

Diante do grande aumento da degradação nestas áreas, faz-se necessário propor medidas de recuperação destes ambientes. Para se propor a recuperação de uma área, faz-se necessário conhecer e quantificar quais os impactos presentes e para isso, a realização de um diagnóstico ambiental é de grande importância.

Segundo Neres et al., (2015), o diagnóstico ambiental é a descrição e análise das condições ambientais presentes no local no momento atual, e pode ser realizada através do levantamento de elementos relacionados ao meio biótico, abiótico e antrópico e de suas influências mutuas.

Benício et al., (2017) aplicaram a metodologia do diagnóstico ambiental para a análise da degradação ambiental, da mata ciliar da represa da Universidade Federal do Tocantins, Gurupi, TO. Os autores relataram que a perda da biodiversidade e a alteração qualitativa da água foram os impactos mais significativos; sendo a supressão da vegetação exótica, o manejo do solo e a revegetação da área, ações indicadas como medidas necessárias para mitigação dos danos ambientais.

Diante do exposto, o presente trabalho objetivou a realização do diagnóstico ambiental e, posteriormente, propor um plano de recuperação de áreas degradadas (PRAD) as margens do Córrego Bananal, no município de Gurupi, TO.

\section{Material e Métodos}

O presente trabalho foi realizado na propriedade rural, Fazenda Carolina 1 e 2, situada às margens da BR-153, do município de Gurupi, Estado do Tocantins. A coleta de dados foi realizada através de visitas técnicas na propriedade, as margens do afluente do Córrego Bananal,

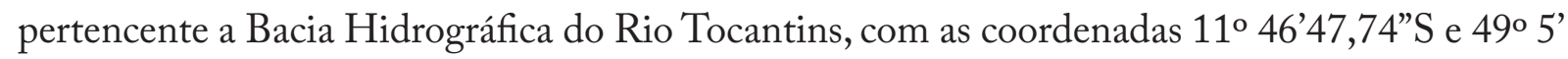
24,48” W, no mês de maio de 2015 (Figura 01). 


\section{Figura 01 - Vista aérea da área de estudo, afluente Córrego Bananal, Fazenda Carolina 1 e 2}

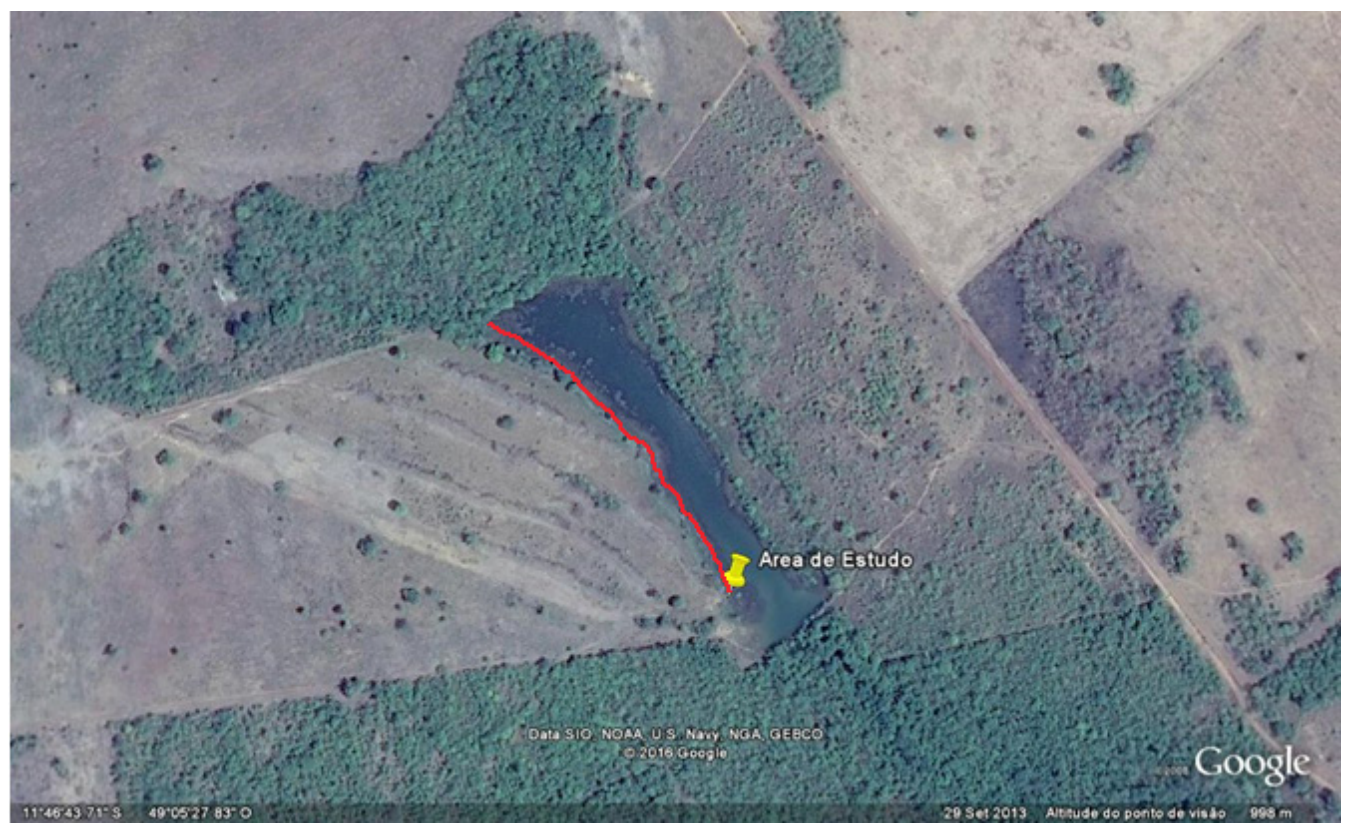

Fonte: Google Earth (2016).

A classificação climática da região, segundo Köppen, é do tipo AW, definida como tropical úmido com estação chuvosa, no verão e seca, no inverno (SEPLAN,2008). A precipitação média anual varia de 1.500 a $1.600 \mathrm{~mm}$ e a temperatura média, ao longo do ano, entre $22^{\circ} \mathrm{C}$ e $28^{\circ} \mathrm{C}$ (SAMPAIO et al., 2011).

De acordo com o Plano Municipal de Água e Esgoto (PMAE, 2013), do município de Gurupi, TO, (2013), o Córrego Bananal é de grande importância para a cidade, por ser um dos mananciais que o município possui e, nele, existe uma represa que atualmente serve de reservatório para abastecer a cidade.

A fazenda abrange uma área de aproximadamente 142 ha. Apesar de a vegetação predominante na região Sul do Tocantins ser a fisionomia de cerrado sensu stricto, são inúmeros os remanescentes de florestas estacionais deciduais, semideciduais, área de tensão ecológica e cerradões, onde se verificam diferentes fisionomias, como formações arbóreas, arbustivas e herbáceas dentro da matriz do domínio Cerrado (Haidar, 2011), encontram-se algumas espécies como: Anadenanthera macrocarpa Benth (angico-preto); Bowdichia virgilioides (sucupira-preta); Dinizia excelsa (Angelim), Tabebuia serratifolia (Ipê Amarelo); Tabebuia róseo alba (Ipê Rosa), Calophyllum brasiliense Cambess. (Guanandi).

Realizou-se o diagnóstico ambiental por meio de visitas técnicas na propriedade e, também, na caracterização da área através de estudo preliminar, observaram-se os possíveis impactos existentes no local. Após a identificação prévia dos impactos, listou-se os mesmos em um caderno e, também foram registrados com fotografias. Essa listagem é conhecida como "Check List" que se baseia na identificação e na enumeração dos impactos encontrados na área relacionados aos meios físicos, bióticos e socioeconômico (Sanchez, 2008), que apresentam uma relação dos impactos mais relevantes no local (POYRY, 2012). 
Após a identificação dos impactos, estes foram classificados de acordo com os critérios de qualificações dos impactos ambientais em ordem, valor, dinâmica, tempo, plástica, espaço, magnitude e importância. A avaliação qualitativa dos impactos foi realizada segundo os parâmetros estabelecidos pela Resolução nº 001/86 (CONAMA,1986) (Tabela 01).

\section{Tabela 01: Parâmetros de análises qualitativas dos impactos observados no Córrego Bananal, município de Gurupi, TO.}

\begin{tabular}{|c|c|c|}
\hline CRITÉRIOS & PARÂMETROS & SIGNIFICADO \\
\hline \multirow{2}{*}{ Ordem } & Direto $(\mathrm{D})$ & Gerada por uma determinada ação \\
\hline & Indireto (IN) & A ação gera indiretamente um impacto \\
\hline \multirow{2}{*}{ Valor } & Positivo $(\mathrm{P})$ & Resulta no benefício de um fator \\
\hline & Negativo $(\mathrm{N})$ & Agrava a qualidade de um fator \\
\hline \multirow{3}{*}{ Dinâmica } & Temporário $(\mathrm{T})$ & Possui duração limitada \\
\hline & Permanente (PE) & Permanece mesmo após cessar a ação. \\
\hline & Cíclico (C) & O efeito se manifesta em intervalos de tempo determinados \\
\hline \multirow{3}{*}{ Tempo } & Curto prazo (CP) & Nota-se o efeito no momento em que se dá a ação \\
\hline & Médio prazo (MP) & Nota-se o efeito algum tempo após ter-se dado à ação \\
\hline & Longo prazo (LP) & Nota-se o efeito muito tempo após ter-se dado à ação. \\
\hline \multirow[b]{2}{*}{ Plástica } & Reversível (R) & Retorna às condições originais depois de cessada a ação \\
\hline & Irreversível (IR) & $\begin{array}{l}\text { Quando o fator ou parâmetro ambiental afetado não retorna } \\
\text { às suas condições originais depois de cessada a ação. }\end{array}$ \\
\hline \multirow{3}{*}{ Espaço } & Local (LC) & $\begin{array}{l}\text { Os efeitos se fazem sentir somente nos arredores do ambiente } \\
\text { onde se dá a ação }\end{array}$ \\
\hline & Regional (RG) & $\begin{array}{l}\text { Os efeitos se fazem sentir além dos arredores do ambiente } \\
\text { onde se dá a ação envolvendo uma determinada região. }\end{array}$ \\
\hline & Estratégico (E) & $\begin{array}{l}\text { Quando seus efeitos têm interesse coletivo ou se fazem sentir } \\
\text { em nível nacional. }\end{array}$ \\
\hline
\end{tabular}

Fonte: Resolução nº 001/86 (CONAMA, 1986).

Para maior compreensão dos impactos observados e analisados, elaborou-se uma rede de interação que visou estabelecer a sucessão de impactos ambientais gerados por uma ação, representados em quadros e diagramas, permitindo retraçar, a partir de um impacto, o conjunto de ações que o causaram (SANTOS, 2013).

A construção da matriz de interação foi realizada através do modelo da matriz de interação de Leopold, et al., (1971) adaptada por Sanchéz (2015), este procedimento permitiu uma breve e ligeira identificação dos problemas ambientais envolvidos na área de estudo, sendo bastante abrangente por envolver aspectos físico, biótico e antrópico. Após a identificação dos possíveis impactos ambientais, a qualificação e a quantificação, propôs-se as medidas mitigadoras para recuperação da área.

Para o diagnóstico da evolução da degradação na presente área realizou-se uma análise temporal, utilizando o Sistema de Informações Geográficas (SIG) que, para Terra et al., (2016), é um instrumento de elaboração eletrônica que permite coleta, gestão, análise e representação automatizada de dados georreferenciados. Flauzino et al., (2010) ressaltam que a utilização de geotecnologias é um instrumento de grande potencial para o estabelecimento de planos integrados de conservação do solo e água, e dos ecossistemas em geral. 
Pelos mapas que foram obtidos pelo programa ArCGis $9.3{ }^{\circledR}$, analisou-se a cobertura vegetal existentes no ano de 1996, 2006 e 2016 e, para extrair o máximo de informações obtidas, utilizou-se a composição com as bandas 3, 4 e 5 .

As imagens utilizadas foram adquiridas no catálogo de imagens do Instituto Nacional de Pesquisas Espaciais (INPE, 2016) sendo imagens do satélite LANDSAT 7 sensores TM (Mapeador Temático) e imagem do (USGS, 2016) - United States Geological Survey - Pesquisa Geológica dos Estados Unidos, sendo imagens do LANDSAT 8.

A tabela 2 apresenta as imagens do INPE, que estão datadas em 15/05/1996 e 23/04/2006, ambas no satélite LANDSAT 7, e a do USGS está datada em 28/05/2016, ou seja, ambas do mesmo período do ano.

Tabela 02: Informações das imagens utilizadas para avaliar a evolução da degradação da área.

\begin{tabular}{cccc}
\hline Ano & Data & Satélite & Fonte \\
\hline 1996 & $15 / 05$ & Landsat 7; Bandas 3,4 e 5 & Catalogo INPE \\
2006 & $23 / 04$ & Landsat 7; Bandas 3,4 e 5 & Catalogo INPE \\
2016 & $28 / 05$ & Landsat 8; Bandas 3,4 e 5 & EarthExplorer \\
\hline
\end{tabular}

Fonte: Próprios autores, 2016.

\section{Resultados e Discussões}

Os principais impactos verificados na área de estudo foram listados pelo "Check List" (Sanche, 2008; Poyry, 2012) e classificados pela Resolução nº 001/86 (CONAMA,1986). Esse método consiste na visualização e na listagem dos impactos ambientais, quando se considera o potencial transformador do ambiente físico biótico e antrópico de ações impactantes conhecidas (SILVA, 1994).

Os maiores impactos observados no Córrego Bananal encontram-se listados e classificados na tabela 3, que foram: supressão da mata ciliar, invasão de espécies ruderais e exóticas, assoreamento e deposição inadequada de resíduos sólidos. 


\section{Tabela 03: Classificação dos impactos observados no Córrego Bananal.}

\begin{tabular}{|c|c|c|c|c|}
\hline \multirow{2}{*}{$\begin{array}{c}\text { Tipos de Impactos } \\
\text { Ambientais }\end{array}$} & \multicolumn{4}{|c|}{ Classificação dos Impactos relacionados no Check List } \\
\hline & 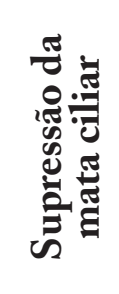 & 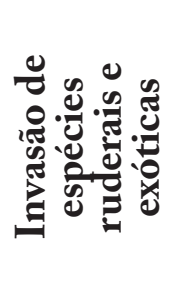 & 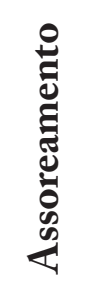 & 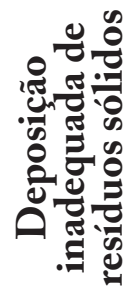 \\
\hline ORDEM & $\mathrm{D}$ & ID & ID & ID \\
\hline VALOR & $\mathrm{N}$ & $\mathrm{N}$ & $\mathrm{N}$ & $\mathrm{N}$ \\
\hline DINÂMICA & $\mathrm{PE}$ & $\mathrm{PE}$ & $\mathrm{PE}$ & $\mathrm{PE}$ \\
\hline TEMPO & $\mathrm{CP}$ & $\mathrm{CP}$ & MP & $\mathrm{CP}$ \\
\hline PLÁSTICA & $\mathrm{R}$ & $\mathrm{R}$ & $\mathrm{R}$ & $\mathrm{R}$ \\
\hline ESPAÇO & RG & $\mathrm{LC}$ & RG & $\mathrm{LC}$ \\
\hline
\end{tabular}

Legenda: D: Direta; ID: Indireta; P: Positivo; N: Negativo; T: Temporário; PE: Permanente; C: Cíclico; CP: Curto Prazo; MP: Médio Prazo; LP: Longo Prazo; R: Reversível; IR: Irreversível; LC: Local; RG: Regional; e E: Estratégico.

\section{Método da Listagem de Controle "Check list"}

Após a classificação dos impactos observados às margens do Córrego Bananal, notou-se que a supressão da mata ciliar (Figura 02) foi considerada um impacto de ordem direta com valor negativo, dinâmica permanente, causando grandes danos ao ambiente, mesmo após cessada a ação em curto prazo de tempo, sendo de plástica reversível em um espaço regional (Tabela 03).

\section{Figura 02 - Mata ciliar suprimida na margem do Córrego Bananal na Fazenda Carolina 1 e 2.}

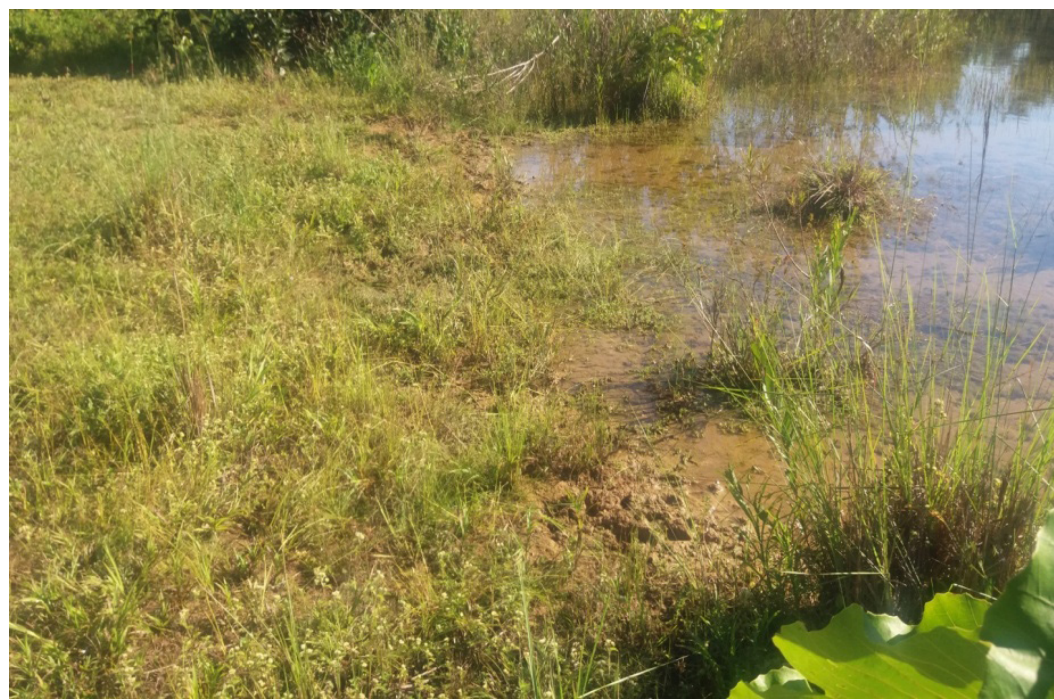

Fonte: Próprios autores (2016)

As matas ciliares exercem diversas funções, sendo uma das principais as ecológicas, pois, garantem a integridade dos recursos naturais bióticos e abióticos do ecossistema, colaborando com a manutenção dos fluxos d'água superficiais e subterrâneos. Agem, também, como barreira física, gerindo os processos de troca entre os ecossistemas terrestres e aquáticos, proporcionando condições adequadas para a infiltração da água (SANTOS et al., 2005). 
Com a retirada da cobertura vegetal das matas ciliares ocorre o desprendimento das partículas do solo, a remoção e transporte destas, e lixiviação, consequentemente, causando o empobrecimento dos nutrientes do solo (VANDERLEY e SILVA, 2015).

Silva e Pazera Júnior (2011) avaliaram a degradação ambiental do Córrego da Bica do Estevão em Arapoema, TO, e relataram que, após o desmatamento da mata ciliar das margens do córrego, ocorreu a diminuição do seu leito e o aumento de suas margens, beneficiando a progressão de processos erosivos.

Às margens do Córrego Bananal, na área de estudo, a invasão de espécies ruderais e exóticas foi considerada como um impacto ambiental de ordem indireta por ser advinda de um impacto direto, a supressão da mata ciliar, com valor negativo, dinâmica permanente em curto prazo, plástica reversível, em um espaço local e suas imediações (Tabela 03).

Uma das espécies encontradas na área foi Baccharia L. (Asteraceae - Astereae), classificada como espécie ruderal por Carneiro e Irgang (2005), Moraes e Monteiro (2006) e Deble (2008). As espécies ruderais se instalam em ambientes altamente perturbados por ação antrópica. Podem ser tanto espécies nativas quanto exóticas. Um local de descarte, um terreno abandonado ou principalmente uma área desmatada, todos podem, inicialmente, serem ocupados por uma comunidade de espécies ruderais que, eventualmente, poderá dar início ao processo de sucessão ecológica (Moro et al., 2012), dependendo da resiliência da área e, também, da composição da matriz vegetacional do local.

Com a presença de espécies ruderais, tornou-se evidente a degradação ocorrida na área de mata ciliar do Córrego Bananal, bem como a presença de espécies exóticas invasoras que se estabelecem em ambientes abertos e com alta intensidade de luminosidade, proliferando-se, dispersando e persistindo, em detrimento de espécies próprias de ecossistemas nativos, causando, assim, alterações nos processos ecológicos (MACK et al., 2000).

As espécies exóticas tomam os espaços das espécies autóctones e, como consequência, ocasiona a perda da biodiversidade nativa, alteram os ciclos e as características naturais dos ecossistemas atingidos, geram mudanças fisionômicas da paisagem natural e trazem grandes prejuízos econômicos (WESTBROOKS, 1998).

Gonçalves et al., (2016), com a realização de diagnóstico ambiental e proposta de plano de recuperação da APP, na fazenda Santa Juliana, Cariri do Tocantins, TO, observaram que a retirada da vegetação nativa, tornou recorrente o surgimento da vegetação exótica invasora.

O assoreamento observado no Córrego Bananal foi considerado impacto ambiental indireto, causado pelo impacto direto de supressão da mata ciliar, apresentando valor negativo, com a dinâmica permanente, em médio prazo e com plástica reversível em espaço regional (Tabela 03).

A retirada da vegetação nativa das Áreas de Preservação Permanente é uma das principais causas que levam ao assoreamento (NOWATZKI et al., 2010). A cobertura vegetal nas margens dos rios, ajuda a proteger o solo, facilitando a infiltração da água. Sem essa proteção, a taxa de infiltração no solo diminui, e consequentemente, aumenta o escoamento superficial, causando processos erosivos, transportes de sedimentos, nutrientes e poluentes para os córregos, rios e reservatórios, podendo ocorrer enchentes e/ou assoreamento (MENEZES, 2010).

Esta cobertura vegetal contribui para a diminuição do processo de assoreamento, reduzindo os impactos das gotas de chuva e enfraquecendo a velocidade do escoamento superficial. Abrandando as perdas de solo pela erosão, protegendo a superfície do solo, impedindo o impacto direto das gotas de chuva sobre a superfície, suavizando a desagregação do solo (FROTA; NAPPO, 2012). 
A deposição de resíduos sólidos no Córrego Bananal (Figura 03) foi considerada um impacto ambiental de ordem indireta, valor negativo, de dinâmica permanente e em curto prazo. Observaram-se os impactos gerados, sendo a plástica reversível cujos efeitos se fazem sentir nos arredores do ambiente, ocorridos num espaço local (Tabela 03).

\section{Figura 03 - Deposição inadequada de resíduos sólidos observados as margens do Córrego Bananal na Fazenda Carolina 1 e 2}

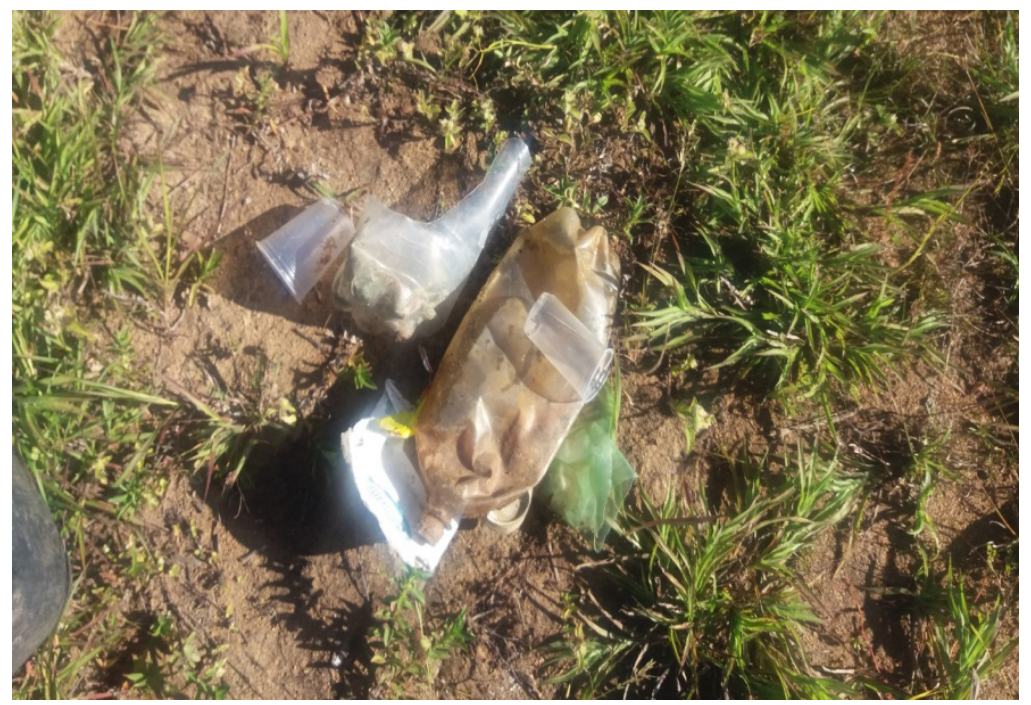

Fonte: Próprios autores (2016)

Notou-se, através da deposição dos resíduos sólidos (Figura 03), que existe a presença constante de pessoas no Córrego Bananal, contribuindo para o processo de degradação, seja por motivo de recreação e/ou pesca, fato evidenciado por estar bem próxima a cidade de Gurupi,TO.

Verificou-se que as ações antrópicas vêm causando efeitos negativos sobre o ambiente, principalmente sobre os recursos hídricos existentes e que, uma das práticas adotadas pelos usuários do local como a deposição inadequada de resíduos sólidos às margens do córrego (Figura 03), de forma direta ou indireta, contribuem para a geração dos impactos observados, principalmente no que se refere à degradação da água e do solo.

De acordo com Mucelin e Bellini (2008), a partir do lixo urbano, muitos impactos ambientais são originados, como: a contaminação de corpos d'água, o assoreamento, as enchentes, a proliferação de vetores transmissores de doenças etc., além da poluição visual, mau-cheiro e contaminação do meio ambiente.

Para Oliveira Junior et al., (2013), os resíduos sólidos são desafios para toda a população do planeta. A coleta e deposição são ações que devem ser eficazes e eficientes para a boa manutenção do equilíbrio ambiental. Entretanto, os poderes públicos, bem como muitas pessoas, não se sensibilizam com o aspecto insalubre provocado.

Neres et al., (2015), realizando o diagnóstico ambiental da nascente do córrego Mutuca, no município de Gurupi, TO, constataram que uma das principais causas da contaminação do corpo hídrico ocorreu pela deposição indevida de resíduos sólidos próxima a nascente, e que esses resíduos foram arrastados pelas enxurradas, ocasionando a poluição das águas. 
Silva et al., (2018) diagnosticaram os principais impactos incidentes na Área de Proteção Permanente (APP) da Fazenda Bom Sossego, município de Formoso do Araguaia, TO. Os principais impactos ambientais identificados foram: o desmatamento irregular, afugentamento da fauna local, compactação da camada superficial do solo, presença de processos erosivos, pisoteamento do solo pelos bovinos e assoreamento do corpo hídrico.

\section{Rede de Interação}

Para Cremonez et al., (2014), os métodos de redes de interações estabelecem relações do tipo causa, condição e efeito, propiciando uma considerável e breve identificação dos impactos indiretos e suas correlações.

A rede de interação forma-se na sequência de efeitos provocados por uma determinada ação, no caso do Córrego Bananal, foi a supressão da mata ciliar, ponto de partida, por meio da qual dela puderam ser observada com maior abrangência as consequências que essa ação acarretou, no meio físico e no meio biótico, observando-se os impactos de primeira, segunda, terceira e demais ordens (Figura 04).

\section{Figura 04 - Rede de Interação dos fatores ambientais observados no Córrego Bananal e os respectivos impactos de segunda, terceira e demais ordens}

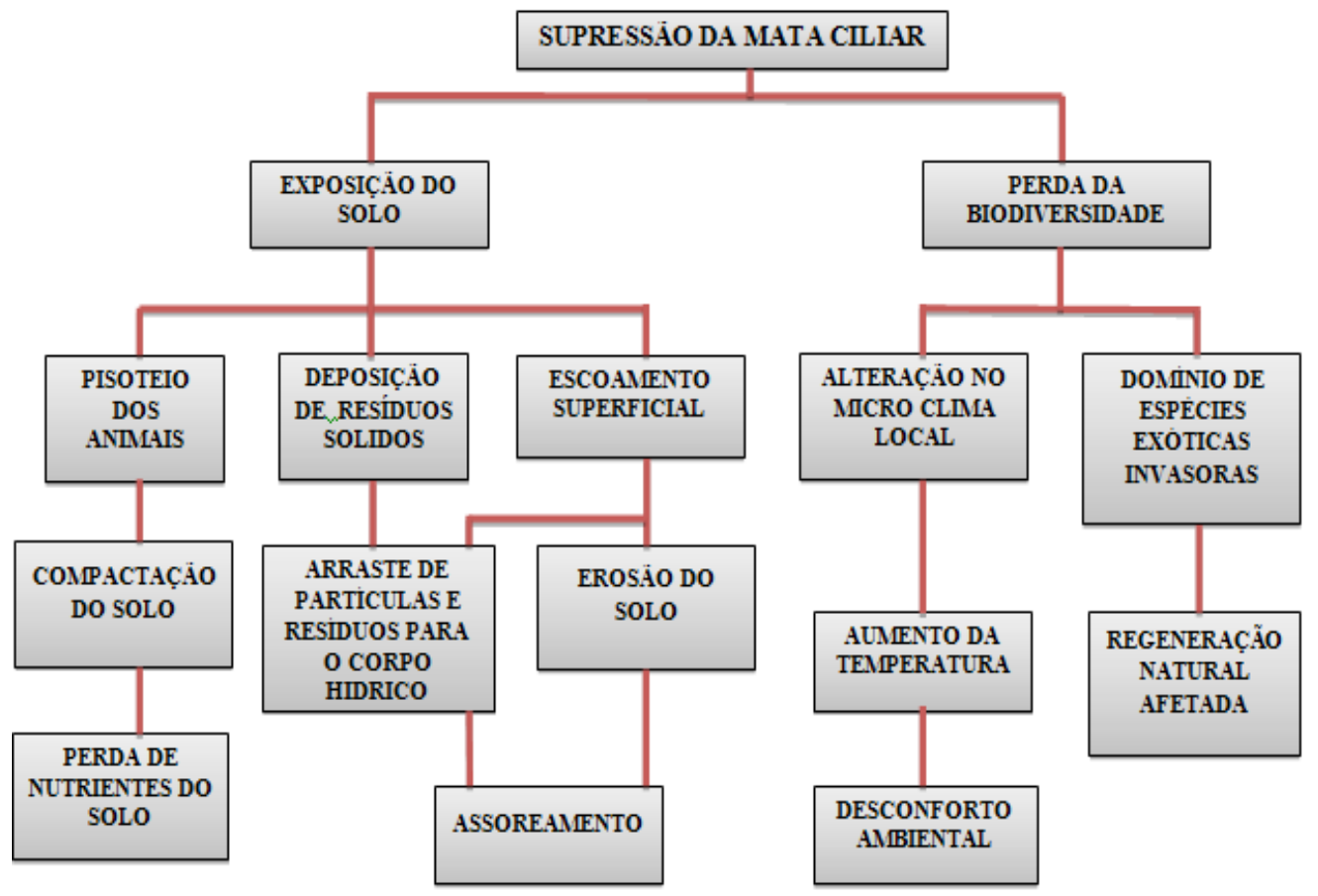

Fonte: Autores (2016)

A supressão da mata ciliar expôs o solo, favorecendo o escoamento superficial, que, por sua vez, causou a erosão e o arraste de partículas para o corpo hídrico, resultando em assoreamento. Com a retirada da vegetação no Córrego Bananal, tornou-se propícia a entrada de pessoas que utilizaram o local para recreação, no qual depositaram restos de alimentos e resíduos sólidos, que 
contaminaram o córrego, além, de ter favorecido a presença de animais que pisotearam o solo, tornando-o compactado e perdendo nutrientes importantes para o desenvolvimento vegetal e, assim, dificultando a regeneração natural.

Em relação ao meio biótico relacionado à biodiversidade, a supressão da mata ciliar levou à perda da biodiversidade, pois favoreceu o domínio de espécies exóticas e invasoras, que impediram que plântulas nativas se regenerassem naturalmente, além, de alterar o microclima local com o aumento significativo da temperatura, aumentando, assim, o desconforto ambiental.

Reis et al., (2015) utilizaram a rede de interação como um dos métodos para diagnosticar os impactos ambientais na nascente do Córrego San Rival, na fazenda Meu Paraíso, em Palmeirópolis, TO, e constataram por meio de fluxograma que foi possível visualizar melhor os efeitos que a retirada da vegetação original causou, tanto no meio físico quanto no meio biótico.

Neres et al., (2015) aplicaram a rede de interação para determinar os impactos ambientais de primeira, segunda, terceira, e demais ordens, na avaliação ambiental da nascente do Córrego Mutuca em Gurupi, TO, visando a indicação de medidas mitigadoras para a área.

De acordo com Rizzeti et al., (2014), a rede de interação é um dos métodos mais empregados para a representação desta cadeia de interação, sendo que os mesmos autores utilizaram o fluxograma para exporem os impactos ambientais observados no desmatamento da mata ciliar na sub-bacia hidrográfica do Rio Soturno.

\section{Matriz de Interação de Leopold}

Para qualificar e quantificar os impactos analisados, utilizou-se a matriz de Leopold et al., (1971), adaptada por Sanchez (2008), cuja metodologia relaciona ações com fatores ambientais e inclui parâmetros de avaliação dos impactos (Tabela 4).

Carvalho e Lima (2010) apresentam as principais desvantagens da matriz de interação de Leopold et al., (1971), que são: sua ampla subjetividade, a falta de avaliação da frequência das interações e a impossibilidade de fazer projeções no tempo. Mas, para Silva; Moraes, (2012) a metodologia apresenta caráter multidisciplinar, baixo custo e simplicidade na elaboração, com orientação correta e disposição visual. Utilizando poucos dados na sua elaboração, sendo eles qualitativos ou quantitativos, permitindo fácil compreensão dos resultados, abordando fatores biofísicos e sociais.

Os maiores impactos quantitativos observados foram no aspecto físico água, com o valor médio de 8,75, tanto para magnitude como para importância, demonstrando a proporção desses impactos nas características ambientais. $\mathrm{E}$ os menores impactos observados foram para o meio antrópico, com valores médios de 7,5 para magnitude e 6,75 para importância (Tabela 04). 


\section{Tabela 4 - Matriz de interação baseada no modelo de Leopold et. al., (1971), adaptada por Sanchez (2008).}

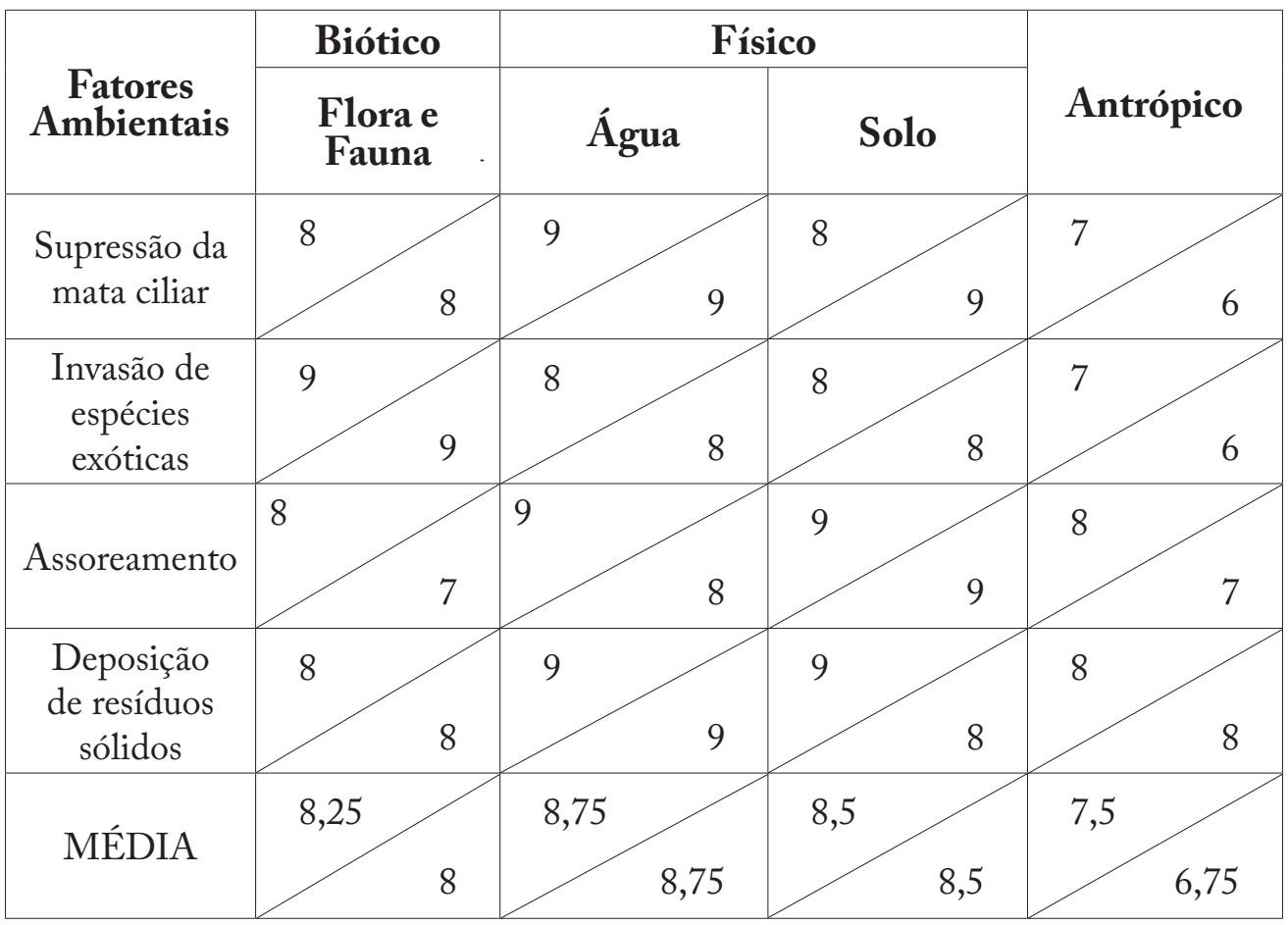

Fonte: Próprios autores (2016)

Através da elaboração e análise da matriz de interação pôde-se perceber que o meio mais afetado foi à água, ocasionado principalmente, pela supressão da mata ciliar que desencadeou impactos de primeira, segunda e terceira ordens. Os impactos menos expressivos foi o meio antrópico, porém, todos esses impactos mencionados agem diretamente ou indiretamente na qualidade de vida da população afetada.

Muitas vezes, a degradação somente é evidenciada com a retirada da vegetação, porém, há uma grande complexidade de fatores bióticos e abióticos envolvidos além da vegetação. $\mathrm{O}$ ecossistema degradado sofre danos no solo, aumentando o assoreamento, a erosão, diminuindo o acúmulo de carbono e de nutrientes; por fim, prejudica os recursos hídricos e a evapotranspiração na atmosfera, mudando completamente o ambiente e dificultando que a floresta se sustente (SANTORI, 2015).

Oliveira et al., (2015) fizeram uso da matriz de interação para seu estudo sobre proposta de recuperação para a nascente do Córrego Mutuca em Gurupi, TO e constataram que os maiores impactos quantificados foram os aspectos bióticos fauna e flora e o menos afetado foi o solo.

Damasceno et al., (2015) utilizaram a Matriz de interação de Leopold et al. (1971) para avaliar os impactos ambientais do processo produtivo do Biodiesel bruto de mamona. Rocha e Kurts (2003) utilizaram para aplicar questionários para a população da microbacia do Córrego Lenhoso em Uberaba, MG, os quais avaliaram as variáveis: ambiental, social, econômica e tecnológica.

Amaral (2018) realizou diagnóstico ambiental da Área de Preservação Permanente e da área de inundação do trecho urbano do rio Paranaíba, no município de Patos de Minas. Entre os impactos ambientais encontrados, citam-se: deposição de resíduos sólidos, presença de espécies exóticas ou invasoras, lançamento de efluentes domésticos e industriais, erosão, assoreamento e pescas. 


\section{Análise Temporal}

A classificação digital supervisionada permitiu analisar a distribuição espacial e quantificar a cobertura da terra ao redor do Córrego Bananal. Os resultados são evidenciados em três mapas que correspondem aos anos de 1996 e 2006 (Figura 05 e 06) e o ano de 2016 (Figura 07).

Em 1996, observou-se que a área apresentava uma extensa e expressiva cobertura vegetal às margens do Córrego Bananal, pois, há 20 anos essas áreas ainda não haviam sido degradadas, notou-se uma área com vegetação densa em relação ao ano de 2006 (Figura 05).

No ano de 2006, as Áreas de Preservação Permanente (APP) tiveram uma vasta supressão vegetal, fato percebido pelo aumento significativo da área do solo exposto. Fato ocorrido devido uma queimada ocasionada nesse período (Figura 06), deixando uma cicatriz de fogo, verificada na imagem datada no dia 09 de maio de 2006.

\section{Figura 05 - Mapa do Córrego Bananal - Fazenda Carolina 1 e 2 - ano 1996 e 2006}
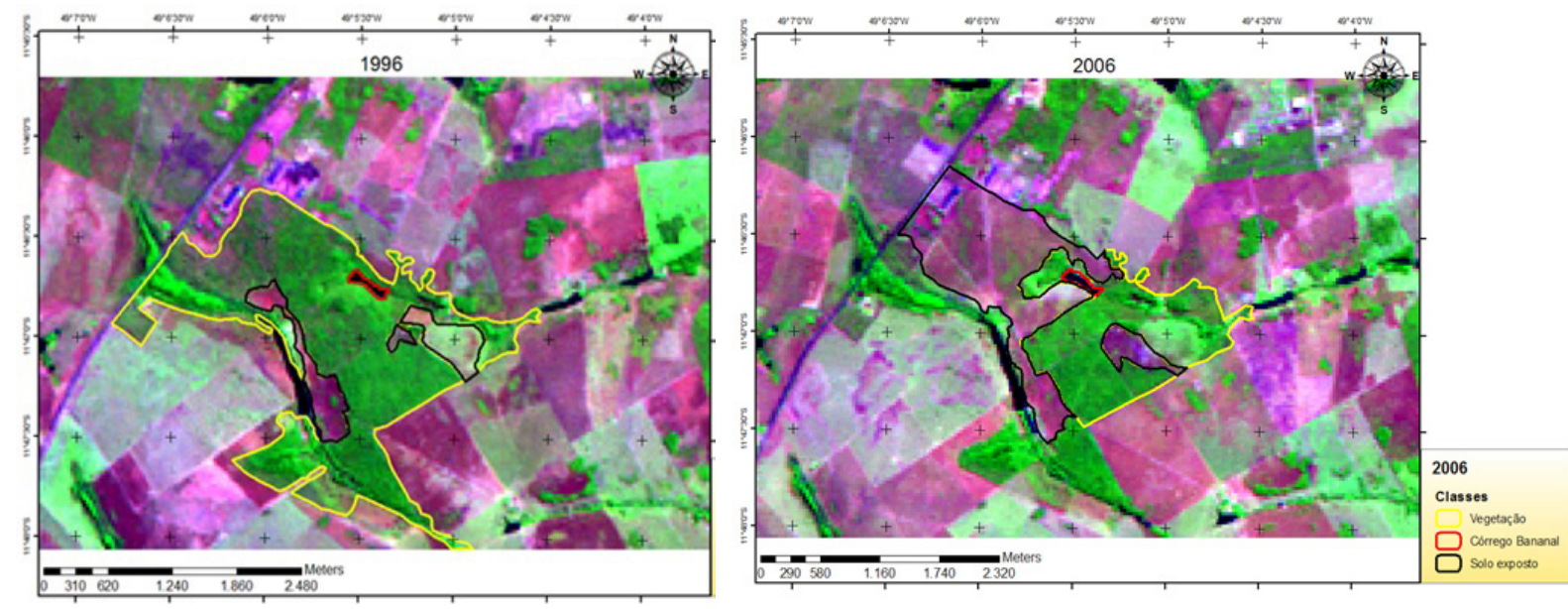

Fonte: Próprios autores (2016) 


\section{Figura 06: Mapa do Córrego Bananal - Fazenda Carolina 1 e 2 demonstrando a cicatriz de fogo no ano de 2006}

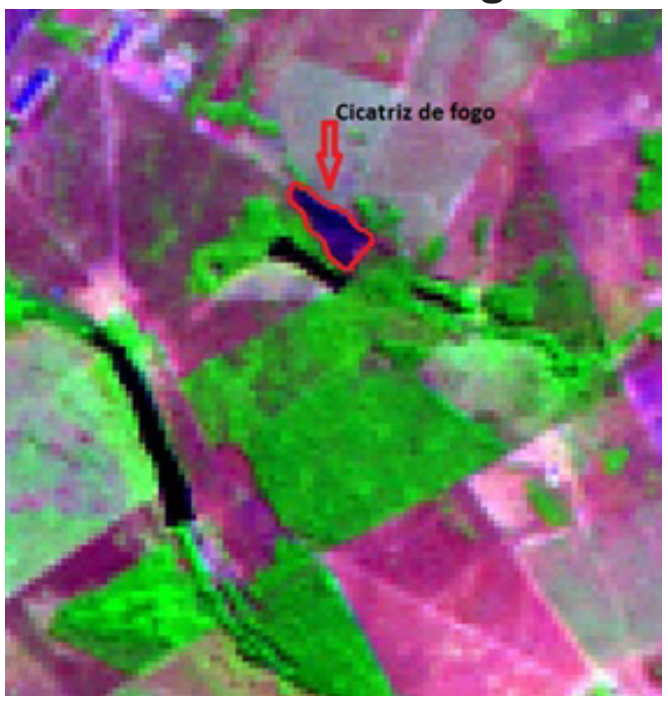

Fonte: Próprios autores (2016)

Na imagem de 2016, evidenciou-se que a área já se encontrava em processo de regeneração natural, em relação ao ano de 2006, pois houve um aumento significativo da cobertura vegetal às margens do Córrego Bananal (Figura 07), porém, não a mesma quantidade de mata original existente no ano de 1996. Sendo que grande parte destas áreas degradadas precisam ser recuperadas, necessitando assim de medidas mitigadoras, a fim de que esse processo ocorra de forma definitiva e satisfatória.

Bonfim et al. (2017) também utilizaram a análise temporal para avaliação dos impactos ambientais causados por um depósito de resíduos sólidos no município de Cariri do Tocantins. Os autores relataram que a análise temporal mostrou que as áreas circundantes do depósito se encontram em processo de recuperação durante os últimos 25 anos, o que indicou que a área onde o lixão está inserido possui resiliência.

Figura 07: Mapa do Córrego Bananal - Fazenda Carolina 1 e 2 - ano 2016.

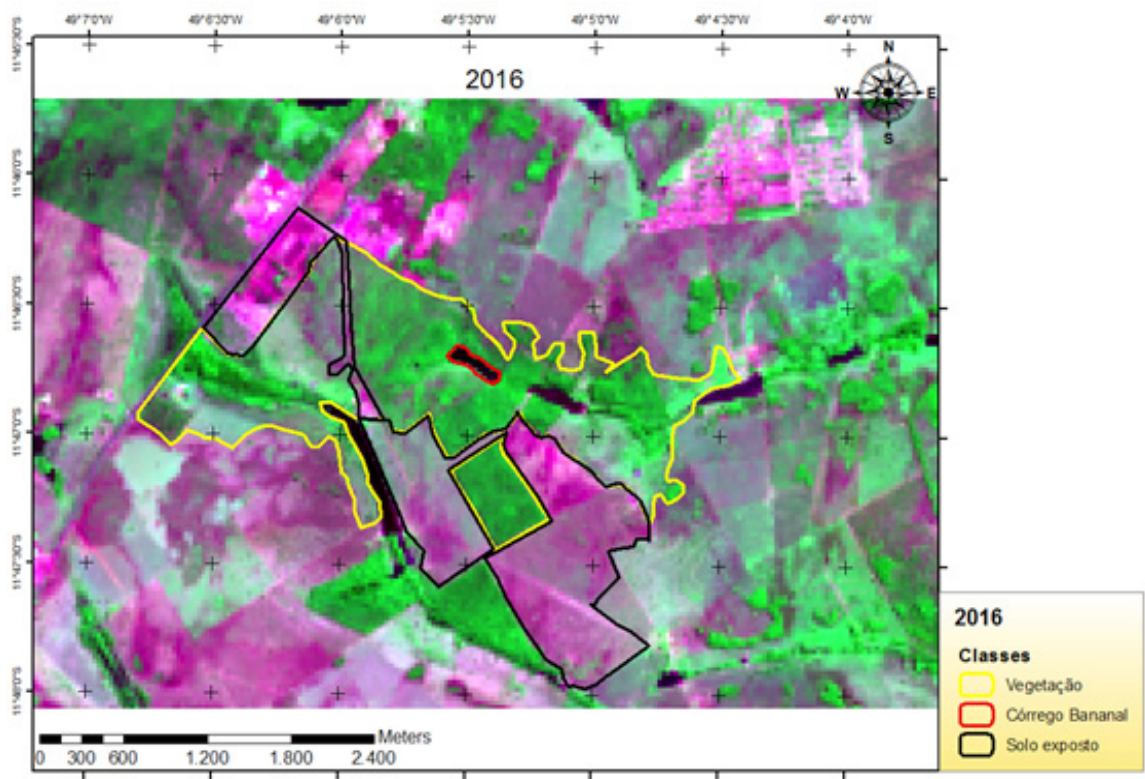

Fonte: Próprios autores (2016) 
Observou-se que o mapeamento temático viabilizou a compreensão dos padrões de organização espacial, com os quais se pode diagnosticar e, até mesmo, prognosticar as mudanças da paisagem e mostrar a distribuição espacial real das diferentes formas de uso dos recursos naturais, cada vez mais alterados pelas ações do homem (TORRES, 2011).

Venturieri e Santos (2008) salientam que a análise temporal do uso e ocupação da terra permite acompanhar a evolução dos padrões de organização do espaço geográfico, facilitando a compreensão de impactos ambientais gerados, em consequência do uso inadequado da terra.

\section{Medidas mitigadoras}

Após a realização da avaliação ambiental da área e dos impactos ambientais analisados, observou-se que são necessárias ações que mitiguem os danos causados, com medidas mitigadoras.

Pelo diagnóstico ambiental realizado no Córrego do Bananal, pôde-se observar que a medida mais indicada para a área foi a medida mitigadora do tipo corretiva, que consiste em restabelecer a situação anterior à ocorrência de um evento adverso sobre o item ambiental destacado nos meios físico, biótico e antrópico (IBAMA, 2004), por meio de ações de controle ou da eliminaçãocontrole do fator gerador do impacto (MARTINS, 2013).

As medidas mitigadoras propostas foram a realização de um Plano de Recuperação de Áreas Degradadas (PRAD), para elaborar estratégias de aplicação a fim de minimizar os danos ambientais nas margens do Córrego Bananal.

Posteriormente, fazer a retirada da vegetação exótica invasora, para que as plântulas nativas existentes se regenerassem. Onde não exista resiliência para se estabelecer a regeneração natural, deve-se realizar o plantio de espécies nativas, diminuindo assim a exposição do solo e consequentemente o assoreamento; isolar toda área ao redor do córrego para evitar a entrada de pessoas e animais, com o intuito de eliminar a deposição inadequada de resíduos sólidos e a compactação do solo por meio do pisoteio dos animais; além de permitir também que bancos de plântulas nativas existentes nas áreas tenham condições de regenerarem. Para conter o assoreamento que ocorre nas margens o ideal é implantar barreiras físicas.

Costa e Pires (2017) realizaram levantamento dos impactos ambientais em área de preservação permanentes (APPs) urbanas em Porangatu, GO. O diagnóstico das áreas comprovou os impactos negativos impulsionados pela expansão urbana, interligados ao crescimento populacional e à expansão territorial. Ressalta-se a necessidade de medidas mitigadoras, potencializadoras de curto, médio e longo prazo envolvendo o poder público, o privado e toda a sociedade local para configurar o desenvolvimento sustentável.

Silva et al., (2018) diagnosticaram os principais impactos incidentes na Área de Proteção Permanente (APP) da Fazenda Bom Sossego, Formoso do Araguaia, TO, e constataram déficit de vegetação na área e como medidas mitigadoras, a recomposição vegetal da fisionomia mata de galeria, isolamento da área com cerca para evitar a entrada do gado e monitoramento da área.

Gomes et al., (2018) realizaram um diagnóstico ambiental da bacia hidrográfica do Córrego Saraiva, Betim, MG, pela identificação e caracterização das principais nascentes e remanescentes florestais. $\mathrm{O}$ estado de conservação das nascentes e dos remanescentes florestais na bacia hidrográfica do Córrego Saraiva foi considerado crítico, sendo necessária a adoção de um planejamento ambiental urbano e rural para subsidiar a gestão do uso e ocupação do solo e a implantação de programas de recuperação ambiental. 


\title{
Conclusões
}

Com a utilização do diagnóstico ambiental para a avaliação dos impactos ambientais ocorridos no Córrego do Bananal, conclui-se que:

Os principais impactos verificados foram: supressão da mata ciliar, invasão de espécies ruderais e exóticas, assoreamento e deposição inadequada de resíduos sólidos.

Através da rede de interação, sequenciram-se os efeitos provocados pela ação de supressão da mata ciliar, ponto de partida, pela qual pôde ser observada, com maior abrangência, as consequências que essa ação acarretou, no meio físico e no meio biótico, observando os impactos de primeira, segunda, terceira e demais ordens.

Com a Matriz de Interação, observou-se que os maiores impactos quantitativos ocorreram no aspecto físico água, com o valor médio de 8,75, tanto para magnitude como para importância. Os menores impactos foram para o meio antrópico, com valores médios de 7,5, para magnitude e 6,75, para importância

A análise temporal demonstrou que o ano de 2006 apresentou maior degradação, quando comparada ao ano de 1996, ocasionada por uma intensa queimada. E que, no ano de 2016, parte da área já se encontrava em processo de regeneração, necessitando, assim, da intervenção antrópica para a recuperação dessas áreas.

As medidas mitigadoras proposta foram: a elaboração de um Plano de Recuperação de Áreas Degradadas (PRAD), a retirada da vegetação exótica, o isolamento de toda área ao redor da represa e o plantio de espécies nativas.

\section{Referências}

\author{
AMARAL, E.A. Diagnóstico ambiental da APP e da área inundável do rio Paranaíba \\ em Patos de Minas/MG e diretrizes para recuperação. 2018. 79 f. Dissertação (Mestrado \\ em Qualidade Ambiental) - Universidade Federal de Uberlândia, Minas Gerais. Disponível \\ em:< https://repositorio.ufu.br/bitstream/123456789/21439/1/Diagn\%C3\%B3stico\%20 \\ ambiental\%20APP.pdf >. Acesso: 05/04/2019.
}

BENICÍO, L.P.B., SOUZA, P.A.; 2, BENDITO, B.P.; SANTOS, A.F., SOUZA, P.B. Análise da degradação ambiental da mata ciliar da represa da Universidade Federal do Tocantins, Gurupi -TO. Enciclopédia Biosfera, Centro Científico Conhecer - Goiânia, v.14 n.26; p. 2017.

BONFIM, C.J.; SOUZA, P.A.; NERES, N.G.C.; GONÇALVES, D.S.; SOUZA, P.B. Diagnóstico ambiental e análise temporal dos impactos ambientais causados por um depósito de resíduos sólidos no município de Cariri do Tocantins. Nucleus, v.14, n.1, abr.125-140p.2017.Disponível em: < http://www.nucleus.feituverava.com.br/index.php/ nucleus/article/view/1736>. Acesso: 05/04/2019.

BRASIL - CÓDIGO FLORESTAL BRASILEIRO - Lei n ${ }^{\circ} \mathbf{1 2 . 6 5 1}$ de maio de 2012. Disponível em: http://www.planalto.gov.br/ccivil_03/_ato2011-2014/2012/1ei/112651. htm Acesso em: 13 jul. 2015. 
CARNEIRO, A. M; IRGANG, B. E. Origem e distribuição geográfica das espécies ruderais da Vila de Santo Amaro, General Câmara, Rio Grande do Sul. IHERINGIA, Sér. Bot., Porto Alegre, v. 60, n. 2, p. 175-188, jul/dez. 2005

CARVALHO, D. L.; LIMA, A. V. Metodologias para Avaliação de Impactos Ambientais de Aproveitamentos Hidrelétricos. Anais... XVI Encontro Nacional dos Geógrafos, Anais...Porto Alegre, 2010.

CASTRO, M. N.; CASTRO, R. M.; SOUZA, P. C.de. A importância da mata ciliar no contexto da conservação do solo. Revista Eletrônica de Educação da Faculdade Araguaia, Goiânia, v. 4, n. 4, p.230-241, dez. 2013.

CONAMA. CONSELHO NACIONAL DO MEIO AMBIENTE (Brasil). Resolução no 001, de 23 de janeiro de 1986. Disponível em: <http://www.mma.gov.br/port/conama/ res/resl> Acesso em: 24 de abril de 2016.

COSTA, M.I.F.; PIRES, M.G. Levantamento dos impactos ambientais em áreas de preservação permanentes (APPS) urbanas em Porangatu - GO. Revista Meio Ambiente e Sustentabilidade, vol. 13, n.6, jun/dez, 2017. Disponível em:<https://www.uninter. com/revistameioambiente/index.php/meioAmbiente/article/viewFile/690/321 >. Acesso: 05/04/2019.

CREMONEZ, F. E.; CREMONEZ, P. A.; FEROLDI, M.; DE CAMARGO, M. P.; KLAJN, F. F. et al. Avaliação de impacto ambiental: metodologias aplicadas no Brasil. Revista Monografias Ambientais, v. 13, n. 5, p. 3821-3830, 2014.

DAMASCENO, N.T. S; SAMPAIO, B. E. O. S; SANTOS, V. M. L. S. Avaliação dos impactos ambientais do processo produtivo do biodiesel bruto de mamona utilizando a Matriz de Leopold. Anais... XXXV ENCONTRO NACIONAL DE ENGENHARIA DE PRODUCAO Perspectivas Globais para a Engenharia de Produção. Fortaleza, CE, Brasil, 13 a 16 de outubro de 2015.

DEBLE, A. S. O. Classificação infragenérica e atualização nomenclatural das espécies brasileiras de Baccharis l. (Asteraceae - Astereae). Tese (Doutorado em Engenharia Florestal) - Universidade Federal de Santa Maria (UFSM, RS), Rio GRand e do Sul, 2008

FLAUZINO, F. S.; SILVA, M. K. A.; NISHIYAMA, L. ROSA, R. Geotecnologias aplicadas à gestão dos recursos naturais da Bacia Hidrográfica do Rio Paranaíba no Cerrado Mineiro. Revista Sociedade \& Natureza, n. 22, p. 75-91. abr. 2010.

FROTA, P.V.; NAPPO, M.E.; Processo erosivo e a retirada da vegetação na bacia hidrográfica do açude Orós - CE. Revista Geonorte, Edição Especial, v.4, n.4, p.1472 $-1481.2012$. 
GOMES, E.C.F.; JESUS, E.N.; OLIVEIRA, N.N.; GONÇALVES JÚNIOR, L.; CABRAL, F.G.S.; RESENDE, M.S.R. Pesq. flor. bras., Colombo, v. 38, p. 1-10, 2018. Disponível em:<https://pfb.cnpf.embrapa.br/pfb/index.php/pfb/article/view/e01309>. Acesso: 05/04/2019.

GONÇALVES, D. S.; SOUZA, P. A. de.; OLIVEIRA, A. L. de.; MARTINS, T. S. Diagnóstico ambiental e proposta de plano de recuperação da APP, Fazenda Santa Juliana, Cariri do Tocantins - TO. Nucleus, Ituverava, v. 13, n. 1, p.261-276, abr. 2016.

GOOGLE EARTH- MAPAS. 2016. Disponível em: http://mapas.google.com. Consulta em: 24/06/2016.

HAIDAR, R. F. Mapeamento e reconstituição dos ambientes fitoecológicos para o sul do estado do Tocantins por meio de imagens LANDSAT MSS e TM e dados geoambientais. Anais... XV Simpósio Brasileiro de Sensoriamento Remoto, Curitiba - PR. P. 201592066, 2011.

IBAMA. (Instituto Brasileiro do Meio Ambiente) Instrução Normativa 2004. Disponível em: http://www.ibama.gov.br/servicos/instrucoes-normativas .Acesso em :23 maio de 2016

IBGE - Instituto Brasileiro de Geografia e Estatística. Gurupi - IBGE Cidades. 2017. Disponível em: <https://cidades.ibge.gov.br/brasil/to/gurupi/panorama>. Acesso em: 05/04/2019.

INPE (Instituto Nacional de Pesquisas Espaciais). Disponível em: http://www.dgi.inpe. br/CDSR/. Acesso em: 24 maio 2016.

JACOMASSA, F. A. F. Espécies arbóreas nativas da mata ciliar da Bacia Hidrográfica do Rio Lajeado Tunas, na região do Alto Uruguai, RS. Biodiversidade Pampeana, Uruguaiana, v. 8, n. 1, p. 1-6, 2010.

LEOPOLD, L.B.; CLARKE, F.S.; HANSHAW, B. et al. A procedure for evaluating environmental impact. Washington: U. S. Geological Survey, 1971. 13p. (circular 645).

MACK, R. N.; CHAIR; S. D.; LONSDALE, W. M.; EVANS, H.; CLOUT, M.; BAZZAZ, F. 2000. Biotic invasions: causes, epidemiology, global consequences and control. Issues in Ecology, 5: 1-20.

MARTINS, S. V. Recuperação de Áreas Degradadas: Ações em áreas de preservação permanente, voçorocas, taludes rodoviários e de mineração. 3 eds. Viçosa- MG. Aprenda Fácil, 2013.

MENEZES. P. H. B. J. Avaliação do efeito das ações antrópicas no processo de escoamento superficial e assoreamento na Bacia do Lago Paranoá. 2010. 117 f. Dissertação (Mestrado Geociências Aplicadas). Instituto de Geociências da Universidade de Brasília. 
MORAES, M. D; MONTEIRO, R. A. A família Asteraceae na planície litorânea de Picinguaba, Ubatuba, São Paulo. Hoehnea, 33 ( I): 41-78, 2006.

MORO, M.F. et al. Alienígenas na sala: o que fazer com espécies exóticas em trabalhos de taxonomia, florística e fitossociologia? ACTA Botânica Brasílica, São Paulo SP, v. 26, n. 4, pp. 991-999, out-dez, 2012

MUCELIN, C. A.; BELLINI, M. Lixo e impactos ambientais perceptíveis no ecossistema urbano. Sociedade \& Natureza, Uberlândia, 20 (1): 111-1 24 jun. 2008.

NERES, N. G. C.; SOUZA; P. A.; SANTOS; A. F. D.; GIONGO; M. \& BARBOSA., L. N. L. Avaliação Ambiental e Indicação de Medidas Mitigadoras para a Nascente do Córrego Mutuca, Gurupi -TO. Enciclopédia Biosfera, Centro Científico ConhecerGoiânia, v.11 n.21; p. 2824, 2015

NOWATZKI, A.; SANTOS, L. J. C.; PAULA, E. V. Utilização do SIG na delimitação das áreas de preservação permanente (APP's) na Bacia do Rio Sagrado (Morretes/PR). Sociedade e Natureza, Uberlândia, v. 22, n. 1, p. 107-120, 2010.

OLIVEIRA, A. L et al. Propostas de recuperação para a nascente do Córrego Mutuca em Gurupi - TO. Enciclopédia Biosfera, Centro Científico Conhecer-Goiânia, v.11 n.21; p. 2824, 2015

OLIVEIRA-JUNIOR, E. S; BUHLER, B. F.; MUNIZ, C. C.; FURLAN, A. Córregos urbanos do município de Cáceres-MT. Brasil: um olhar para a conservação, Mato Grosso, MT. REGET, v. 17 n., p. 3268- 3274, 17 Dez, 2013.

PMAE - Plano Municipal de água e esgoto - Prefeitura municipal de Gurupi - TO, 2013. Disponível em : http://www.gurupi.to.gov.br/resources/arquivos-publicados/planosmunicipais/agua_esgoto_2013.pdf Acesso em : 22 de maio de 2016.

POYRY Tecnologia Ltda. Estudo de impacto Ambiental - EIA Industrial Volume III - Avaliação de impactos. Klabin - papel e celulose Projeto puma - PR. 133P. 2012. Disponível em:< http://www.klabin.com.br/mediabase/RIMA-relatorioimpactoambiental.pdf $>$. Acesso em: 22 de maio de 2016.

REIS, Amanda da Silva et al. Impactos Ambientais diagnosticados nas nascentes do córrego San Rival: Fazenda Meu Paraíso, Palmeirópolis - TO. Enciclopédia Biosfera, Centro Científico Conhecer, Goiânia - GO, v. 11, n. 21, p.3166-3184, 01 jun. 2015

RIZZETI, D. M.et al. Impactos Ambientais na sub-bacia hidrográfica do Rio Soturno decorrentes do desmatamento da mata ciliar. Anais... FÓRUM INTERNACIONAL ECOINOVAR, 3. Santa Maria/RS - 3 a 4 set. 2014. 
ROCHA, J.S.M.; KURTZ, S.M.J.M. Curso de Manejo Integrado de Bacias Hidrográficas: aplicações técnicas avançadas em diagnósticos físicos conservacionista, sócio-econômico, ambiental. Santa Maria: Universidade Federal de Santa Maria UFSM, 2003.

SALERA JÚNIOR, G. Recanto das Letras. Recursos Hídricos de Gurupi. 2011. Disponível em: <https://www.recantodasletras.com.br/artigos/1325204>. Acesso em: 05/04/2019.

SAMPAIO, M. S.; ALVES M, C; CARVALHO, L. G.; SANCHES, L. Uso de sistema de informação geográfica para comparar a classificação climática de Koppen-Geiger e de Thornthwaite. Anais... XV Simpósio Brasileiro de Sensoriamento Remoto, 2011, Paraná. Curitiba: SBSR, INPE. 2011, p. 8857 - 8864.

SANTORI, R. A. Guia Prático para Elaboração de Projeto de Recuperação de Áreas Degradadas (PRAD) em APP. Nota Técnica n. ${ }^{\circ}$ 03/2015. 2015. Disponível em: http:// www.amazonia-ibam.org.br/images/pqga/noticias/2015/03/003_prad.pdf Acesso em: 26 de maio de 2016

SANCHEZ, L.E. Avaliação de Impacto Ambiental: conceitos e métodos. São Paulo: Oficina de textos, 2008.p 452.

SÁNCHEZ, L. E. Avaliação de Impacto Ambiental. Oficina de Textos, 2015. p. 584

SANTOS, M. C. V. dos.; SILVA, N. M. da.; RODRIGUES, R. Análise comparativa da recuperação de trecho de mata ciliar (Rio Cuiabá, Cuiabá - MT) em quadrantes submetidos a diferentes condições de manejo. Cadernos de Publicações Univag, Várzea Grande, n. 2, p.102-113, 2005.

SANTOS, I. D. C. A avaliação de impacto ambiental e a responsabilidade do Brasil diante da degradação ao meio ambiente. Interfaces Científicas - Direto, Aracaju. v.1, n. 2, p. 67-74, 2013.

SEPLAN - Secretária do Planejamento. Diretoria de Zoneamento Ecológico- Econômico - (DZE) Base de dados geográfico do TO. Versão 2008, Palmas- TO Disponível em : http://seplan.to.gov.br/ Acesso dia: 13.04.2016.

SILVA, A. L. E.; MORAES, J. A. R. Proposta de uma matriz de avaliação de impactos ambientais em uma indústria plástica. Anais... XXXII ENCONTRO NACIONAL DE ENGENHARIA DE PRODUÇÃO, 2012, Bento Gonçalves - RS. Desenvolvimento Sustentável e Responsabilidade Social: As Contribuições da Engenharia de Produção. Bento Gonçalves - RS: Enegep, 2012.p. 1 - 13. 
SILVA, E. Avaliação qualitativa de impactos ambientais do reflorestamento no Brasil. 1994. 309 f. Tese (Doutorado em Ciência Florestal) - Universidade Federal de Viçosa, Viçosa, MG: 1994.

SILVA, M. C. d.; PAZERA JÚNIOR, E. Levantamento da degradação ambiental do córrego da Bica do Estevão no Município de Arapoema -TO. IN: MACHADO, C. A.; SIEBEN, Airton (orgs). Desenvolvimento regional e urbano. Kelps, 2011. 344 p.

SILVA, T.G.N.; GAMA, R.C.; TEIXEIRA, L.G.; SANTOS, G.R.; SOUSA, R.M.; SOUZA, P.B. Diagnóstico ambiental de uma área de Proteção Permanente (APP), Formoso do Araguaia - TO. Revista da Universidade Vale do Rio Verde, v. 16, n. 2. Ago/dez. 2018. Disponível em:<http://periodicos.unincor.br/index.php/revistaunincor/ article/view/4619 >. Acesso: 05/04/2019.

TERRA, L. G; SCHIAVO, B. N.V; BORBA, W.F.; DUARTE, M.M. Geoprocessamento algébrico utilizado na caracterização da fragilidade Ambiental do município de SantiagoRS. Revista Caminhos de Geografia. Uberlândia - MG v. 17, n. 57 Mar/2016 p. 167-174 Página 167. ISSN 1678-6343

TORRES, D. C. Análise multitemporal do uso da terra e cobertura florestal com dados dos satélites LANDSAT e ALOS. 2011. 96f. Dissertação (Mestrado em Engenharia Florestal). Universidade Federal de Santa Maria, Santa Maria, RS.

USGS (United States Geological Survey), Disponível em: http://earthexplorer.usgs.gov/ Acesso dia: 24 de maio de 2016.

VANDERLEY, L. D. M.; SILVA, M. C. da. Degradação ambiental no córrego Mato Verde em Babaçulândia - TO. Geo Amazônia, Belém, v. 3, n. 5, p.52-62, 2015.

VENTURIERI, A.; SANTOS, J. R. dos. Técnicas de classificação de imagens para análise da cobertura vegetal. Sistemas de Informações Geográficas: Aplicações na Agricultura. 2 ed. Brasília: EMBRAPA, 1998. p. 351 - 371. 2008

WESTBROOKS, R. Invasive plants: changing the landscape of America: fact book. Washington: Federal Interagency Committee for the Management of Noxious and Exotics Weeds, 1998. 107p. 